EGU2020-2998

https://doi.org/10.5194/egusphere-egu2020-2998

EGU General Assembly 2020

(c) Author(s) 2020. This work is distributed under

the Creative Commons Attribution 4.0 License.

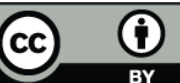

\title{
Airborne Measurements of Formaldehyde In Biomass Burning and Urban Plumes In Central Africa Using Laser Induced Fluorescence
}

Grace Ronnie ${ }^{1}$, Lisa Whalley ${ }^{1}$, Dwayne Heard ${ }^{1}$, Trevor Ingham¹ , James Lee ${ }^{2}$, Dominka Pasternak², Stéphane Bauguitte ${ }^{3}$, Rebecca Carling ${ }^{3}$, Thomas Bannan ${ }^{4}$, Huihui $\mathrm{Wu}^{4}$, and Alexander Archibald ${ }^{5}$

${ }^{1}$ University of Leeds, School of Chemistry, United Kingdom of Great Britain and Northern Ireland (g.v.ronnie1@leeds.ac.uk)

${ }^{2}$ University of York, Wolfson Atmospheric Chemistry Laboratories, United Kingdom of Great Britain and Northern Ireland

${ }^{3}$ Facility for Airborne Atmospheric Sciences, Cranfield University, United Kingdom of Great Britain and Northern Ireland

${ }^{4}$ University of Manchester, School of Earth, Atmospheric and Environmental Sciences, Centre for Atmospheric Science,

United Kingdom of Great Britain and Northern Ireland

${ }^{5}$ University of Cambridge, Department of Chemistry, United Kingdom of Great Kingdom and Northern Ireland

Formaldehyde is a key intermediate in photochemical oxidation of volatile organic compounds in the troposphere and is also directly emitted by a range of sources, including biomass burning and fuel combustion. Airborne measurements of formaldehyde have therefore been used to investigate oxidation in biomass burning (BB) plumes intercepted during the Methane Observations and Yearly Assessments (MOYA) campaign. The MOYA campaign took place January/February 2019 in Uganda and Zambia and mixing ratios of formaldehyde were obtained using the University of Leeds formaldehyde Laser Induced Fluorescence (LIF) instrument. A range of air masses were intercepted including multiple near-field biomass burning (BB) plumes, with up to $140 \mathrm{ppb}$ of formaldehyde observed, and urban emission plumes from the capital city of Kampala in Uganda, where up to 7 ppb of formaldehyde was measured. Formaldehyde emission factors have been calculated for Ugandan BB $\left(1.20 \pm 0.23 \mathrm{~g} \mathrm{~kg}^{-1}\right)$ which agree well with literature $\left(1.23 \pm 0.65 \mathrm{~g} \mathrm{~kg}^{-1}\right)$ for Savannah combustion. Production of formaldehyde as a function of plume age has also been investigated in order to discriminate direct emission from photochemical formation in BB plumes. BB plumes were also intercepted during other aircraft campaigns several days downwind of emission such as a plume transported from Canadian wildfires observed in the North Atlantic during ACSIS-5/ARNA-1 where levels of up to $18.30 \mathrm{ppb}$ were detected, indicative of sustained photochemical oxidation within the plume. Comparison of urban, near-field BB and farfield BB plumes provides a variety of environments and photochemical ages to test our understanding of combustion oxidation processes. 